\title{
Draft of next corporate plan
}

\section{London}

A DRAFT of the 1991-96 corporate plan from the British Natural History Museum (NHM) predicts a cumulative loss in real terms in government funding of $£ 7.2$ million by 1996 , despite huge efforts to streamline organization and raise money from external sources. This figure assumes that the government will continue failing to keep the NHM's grant-inaid in line with inflation. But the draft also makes clear that the museum does not consider further staff cuts to be an option.

"In all areas of its activities the museum's staffing levels are at the minimum required to achieve its strategy", it says. "Further staff cuts to meet the potential funding deficit in 1995-96 would not be possible without the elimination of key $X$-RAY ASTRONOMY

\section{ROSAT's return}

\section{London}

THE multinational Röntgen orbiting Xray observatory ROSAT resumed observations at 4:20 GMT last Saturday (9 February) after the malfunction on 25 January that damaged two instruments (see Nature 349, 445; 7 February 1991).

With the accident happening just one week short of the completion of the initial all-sky survey phase, ROSAT mission planners have decided to shelve the remaining week and move straight on to the second phase, a programme of detailed observations of individual sources. Even though only one day will have been lost in the timetable, researchers are proceeding very cautiously. For example, the British ultraviolet-sensitive wide-field camera will use only one of its filters, the S1 filter with a mean pass wavelength of 100 angstroms. This strategy will save the S2, 140angstrom filter, the twin of which was damaged in the accident. This temporary precaution will be in operation for a week or so until new safeguard procedures can be implemented.

Together with the other packages, the remaining German X-ray detector (the other having been destroyed by sunlight in the accident) and the US high-resolution imager, ROSAT will be used to study a wide range of objects from distant quasars to the interstellar medium.

Exactly why ROSAT went wrong is still a mystery, but scientists decided to proceed with caution rather than hold up the mission any further. The National Aeronautics and Space Administration has agreed to make the Deep Space Network available for tracking the satellite, so that the period when the spacecraft can be tracked will be extended from 8 to 16 hours out of 24 . activities". The unpublished confidential draft has still to be approved by trustees before a final version can be produced and submitted to the Office of Arts and Libraries (OAL) in April. It acknowledges the low morale of staff following the reorganization last year that resulted in the loss of one in six science research posts (see Nature 344, 805; 1990). The museum shed 50 posts between 1983 and 1989 , and a further 100 between 1989 and 1991 . "With a new complement of around 730 by the end of 1991-92, the Museum has gone as far as it can", the draft says.

Staff have given the draft plan a cautious welcome inasmuch as they were permitted a period of consultation before the final version is produced. The rather more secretive formulation last year of the 1990-95 plan caused considerable resentment, particularly in the scientists' trade union, the Institution of Professionals, Managers and Specialists (IPMS).

Only one museum scientist, zoologist Andy Stimson, was faced with compulsory redundancy once the provisions of the 1990-95 plan had been implemented, although the fate of several other staff members is still in doubt, particularly those given temporary reprieves. There is still "unfinished business", says IPMS branch chair Penny Wheatcroft. This includes a forthcoming government inspection of fluidly graded posts next autumn. A bone of contention between the IPMS and the management is the latter's intention to fix the grades of many posts. Fixed grading makes management structures easier to control, but makes promotion in the same subject area on the basis of merit extremely difficult.

Most other researchers were found alternative jobs, many of which are managerial. A $£ 10,000$ independent report on museum training identifies the lack of experience in management as a possible cause of continuing low morale at the museum. "It says lots of things we've been saying for years", Wheatcroft says. The report also highlights the need for more effective communication between senior management and staff. The NHM has earmarked $£ 90,000$ to implement a comprehensive management training programme to meet these needs.

The museum's science programme will, despite intense criticism during the past year, continue to be focused on six subject areas: biodiversity, environmental quality, living resources, mineral resources, human health and human origins. The draft highlights many recent successes by NHM scientists in securing external collaboration and funding for particular research projects. Approximately £1 million was raised in 1990-91 in the form of grants, contracts and sponsorship, inclu- ding $£ 300,000$ from the Wellcome Trust and the Natural Environment Research Council for molecular phylogeny studies.

But a more comprehensive document detailing scientific activity at the NHM is still awaited. The draft notes the preparation, now in hand, of an Annual Report on Science "for a wide audience that needs to be informed about the work of the Science Departments". The report is expected to be issued early in the next financial year.

Henry Gee

INDIAN RESEARCH

\section{Universities and Industry collaborate}

New Delhi

A HISTORIC compact between the University Grants Commission (UGC) and the Council of Scientific and Industrial Research (CSIR) is expected to narrow the gulf between academic and industrial research in India. This past week, the two agencies, which account for more than half of scientific research manpower, entered into an agreement to tap each other's capability, material and human resources.

The CSIR oversees 40-odd national laboratories and institutes geared to research, both basic and applied, aimed at boosting industrial production. These institutes have been virtually isolated from university research departments funded by the UGC. The new arrangement seeks to provide fruitful interaction between the university system and national laboratories.

To begin with, the CSIR will expose the academic community to applied research by establishing research facilities in select areas in university departments. In addition, the CSIR will develop collaborative research projects with university faculty members and throw open its libraries, workshops, computers and laboratory facilities to research scholars. University teachers and researchers will also be invited to spend short periods in national laboratories.

In turn, the UGC will provide CSIR scientists with free access to interuniversity centres and will allow the applied scientists of CSIR to guide research students towards a degree. The UGC has agreed to give academic recognition to CSIR scientists by instituting a programme of visiting, adjunct and honorary professorships.

A 15-member coordination body headed by UGC chairman Professor Yash Pal has been set up to implement the scheme. The CSIR director-general is the co-chairman of the body, whose other members consist of university vice-chancellors, directors of national laboratories, and eminent scientists nominated by the UGC and CSIR. "It is a historic agreement", said Pal after the signing ceremony.

K. S. Jayaraman 